\title{
Solid Particle Impact Erosion of Thermally Sprayed Heating Elements Reinforced with Ceramic Particles
}

\author{
S. Taghian Dehaghani ${ }^{1 *}$, A. Dolatabadi ${ }^{2}$, A. McDonald ${ }^{1}$ \\ ${ }^{1}$ Department of Mechanical Engineering, University of Alberta, Edmonton, Canada \\ ${ }^{2}$ Department of Mechanical, Industrial and Aerospace Engineering, Concordia University, Montreal, Canada \\ *taghiand@ualberta.ca
}

\begin{abstract}
Ice accretion on the surface of wind turbine blades and aircraft wings in cold environments results in unwanted outcomes such as decreases in efficiency, performance, and undermines safety. Thermally sprayed heating elements could be used in manufacturing reliable, efficient, and controllable de-icing systems. However, the surface of these coating-based heating systems will be exposed to surface degradation involving solid particle impact erosion. This type of erosion may lead to significant surface material degradation, and therefore, needs to be addressed. In this study, nickel-chromium-aluminum-yttrium (NiCrAlY) powder was selected for fabrication of coating-based heating elements. With NiCrAlY as the metal matrix material, a ceramic powder namely, aluminum oxide and a cermet powder namely, tungsten carbide-cobalt (WC-12Co), were mechanically blended with the NiCrAlY powder in separate containers. The flame spraying technique was used to deposit these powders on the surface of carbon steel round bars. A low-pressure cold spraying unit was used for erosive particle (garnet sand) impingement on the substrates. A scanning electron microscope (SEM) was used to study the microstructure of the coatings. The erosion resistance of the coatings was determined by measuring the amount of mass loss during the erosion tests. It was observed that the amount of mass loss in the NiCrAlY-WC-12Co coating was considerably less than that of the NiCrAlY coating. However, the experimental data showed that there was no significant difference between the mass loss of NiCrAlY-alumina and NiCrAlY coatings. These results suggest that thermally sprayed metal matrix composite coatings can be effectively implemented for improving the erosive wear resistant of coating-based heating systems.
\end{abstract}

Word count: 257 